\title{
EDITORIAL
}

\section{EL INTERNET DE LAS COSAS OPORTUNIDADES Y DESAFÍOS}

El concepto de Internet de las cosas (IOT), "describe la interconexión de objetos físicos del mundo real con la Internet", este término fue acuñado por primera vez en el año 1999 por Kevin Ashton. Si bien para ese entonces las redes de telecomunicaciones estaban en su estado incipiente, a duras penas los ordenadores se conectaban por la red telefónica conmutada (RTC), con anchos de banda en rangos desde $1 \mathrm{kbps}$ hasta $56 \mathrm{kbps}$ (kilobits por segundo). Era inverosímil pensar que se pudiera conectar cualquier objeto a la red y transmitir información. Sin embargo, esa visión de Kevin Ashton se ha empezado a materializar en los últimos años, gracias a avances en la nanotecnología y sus implicaciones en las infraestructuras de red; con mayores velocidades de anchos de banda y ubicuidad en la conectividad soportada por redes de cuarta y quinta generación ( $4 G$ y $5 G$ ), teniendo en cuenta que las últimas aún se encuentran en desarrollo. Actualmente, los dispositivos han mejorado enormemente su capacidad de procesamiento, almacenamiento y transmisión, permitiendo así conectar cualquier objeto a la red de Internet. Hoy ya se puede obtener información en tiempo real sobre datos de variables ambientales distribuidas en el mundo, que permiten saber el estado del tiempo. De igual forma, se puede saber de forma inmediata el estado del tráfico de una ciudad, el nivel de combustible de un vehículo, el ritmo cardiaco de un paciente, los alimentos próximos a vencer en un refrigerador, la ubicación de un animal o una persona y cualquier cantidad de información que requiera ser medida. A continuación se listan importantes áreas de trabajo en aplicaciones loT:

- Domótica

- Automóviles autónomos

- Plantas de producción industrial

- Logística (trazabilidad de paquetes, cadenas de frio de alimentos y medicamentos entre otras)

- Planeación urbana

- Administración de desechos

- Administración de producción

- Salud

- Restaurantes

- Compras

- Agricultura

- Educación

- Monitoreo de variables ambientales

Esta interconexión de objetos permite tener información sobre el estado de los mismos, pero a la vez plantea una serie de desafíos:

- Transición al protocolo de internet versión 6 (IPV6)

- Reducir los costos exagerados en consumo de energía (eficiencia energética) 
- Diseño de hardware robusto para el procesamiento y transmisión (aunque en la actualidad los dispositivos cuentan con buenas prestaciones, siguen siendo limitados)

- Privacidad y seguridad

- Almacenamiento y gestión de datos (Big data)

JORGE GÓMEZ GÓMEZ EDITOR
ISAAC CAICEDO CASTRO

COEDITOR 